\author{
SERIES 'LUNG HYPERINFLATION IN AIRWAY OBSTRUCTION' \\ Edited by V. Brusasco and J.W. Fitting \\ Number 6 in this Series
}

\title{
Pulmonary hyperinflation and ventilator-dependent patients
}

\author{
A. Rossi*, A. Ganassini*, G. Polese**, V. Grassi+*
}

Pulmonary hyperinflation and ventilator-dependent patients. A. Rossi, A. Ganassini, G. Polese, V. Grassi. CERS Journals Ltd 1997.

ABSTRACT: Pulmonary hyperinflation is a major medical problem in patients with advanced chronic obstructive pulmonary disease (COPD) or acute asthma. The apparent beneficial effects of pulmonary hyperinflation on lung mechanics, such as an increased airway patency and lung elastic recoil, are by far overwhelmed by the deleterious effects on the pressure generating capacity of the respiratory muscles. Moreover, the ventilatory workload can be remarkably increased: 1) by the displacement of the respiratory system toward the upper, flat portion of the pressure-volume curve; 2 ) by the need to expand the chest wall and not only the lungs; and 3 ) by the intrinsic positive end-expiratory pressure (PEEPi) systematically associated with dynamic hyperinflation.

In mechanically ventilated patients, the mechanisms underlying pulmonary hyperinflation as well as its pathophysiological consequences do not differ from those described in spontaneously breathing patients. However, there are some specific issues that should be taken into account, namely the effect of the endotracheal tube and the mode and setting of the ventilator. In mechanically ventilated patients, pulmonary hyperinflation increases the risk of barotrauma and may hamper weaning due to the excessive burden of PEEPi, which can even lead to ineffective inspiratory efforts.

Because of its harmful consequences, pulmonary hyperinflation must be treated aggressively by pharmacological therapy and, when needed, by ventilatory treatment. The setting of the ventilator must be predetermined to ensure the longest possible time for expiration, and positive end-expiratory pressure can be applied to prevent an excessive workload for the patient and ineffective inspiratory efforts. Eur Respir J 1997; 10: 1663-1674.
*Servizio di Fisiopatologia Respiratoria, Divisione di Pneumologia, Ospedale Maggiore, Verona, Italy. **Servizio Pneumotisiologico ULSS 20, Verona, Italy. ${ }^{+}$Cattedra di Medicina Interna, Università di Brescia, Italy.

Correspondence: A. Rossi

Divisione di Pneumologia

Ospedale Civile Maggiore di Borgo Trento

Azienda Ospedaliera di Verona

P.le Stefani 1

I-37126

Verona

Italy

Keywords: Intrinsic positive end-expiratory pressure

mechanical ventilation

pulmonary hyperinflation

respiratory failure

respiratory mechanics

Received: February 241997

Accepted for publication April 21997

This work was supported by grant No. 407 Telethon, Rome, Italy.
In normal subjects, during tidal ventilation, the elastic energy stored in the respiratory system during the preceding inspiration is sufficient for expiration. The functional residual capacity (FRC), which is the amount of gas in the lungs and airways at the end of a spontaneous expiration, is determined by the opposing elastic forces of the lungs and chest wall, thus corresponding to the static equilibrium volume of the total respiratory system (or "relaxation volume") (Vr) [1]. Pulmonary hyperinflation is defined as an increase in FRC above the predicted value, even above the predicted total lung capacity (TLC). Dynamic pulmonary hyperinflation is defined as an increase in the end-expiratory lung volume (EELV) above $V$ r, due mainly to a discrepancy between the time needed to decompress the lungs to $V_{\mathrm{r}}$ and the time actually available between two inspirations (or mechanical lung inflations) [2].

Pulmonary hyperinflation is a common feature in patients with emphysema and advanced chronic obstructive pulmonary disease (COPD) [3]. Dynamic pulmonary hyperinflation occurs during acute exacerbations of COPD $[3,4]$, and in patients with acute asthma attacks [5]. In ventilator-dependent patients, dynamic pulmonary hyperinflation may be found not only in patients with airway disease, such as asthma or COPD, but also in patients with acute lung failure (ARF) or acute respiratory distress syndrome (ARDS) [6]. The mechanisms leading to pulmonary hyperinflation in ventilator-dependent patients, and its possible pharmacological and physiological treatment will be examined in this article.

\section{Background}

Pulmonary hyperinflation has different causes, such as changes in the elastic and resistive properties of the lungs and the chest wall or changes in the timing and pattern of activation of respiratory muscles [3, 7], and bears relevant clinical consequences.

\section{Causes of pulmonary hyperinflation}

Major causes of pulmonary hyperinflation are: 1) the loss of lung elastic recoil; 2) abnormal airflow resistance; and 3) short expiratory time.

Previous articles in this series: No. 1: G.J. Gibson. Pulmonary hyperinflation a clinical overview. Eur Respir J 1996; 9: 2640-2649. No. 2: E.W. Russi, U. Stammberger, W. Weder. Lung volume reduction surgery for emphysema. Eur Respir J 1997; 10: 208-218. No. 3: R. Pellegrino, V. Brusasco. On the causes of lung hyperinflation during bronchoconstriction. Eur Respir J 1997; 10: 468-475. No. 4: A. de Troyer. Effect of hyperinflation on the diaphragm. Eur Respir J 1997; 10: 708-713. No. 5: M. Decramer. Hyperinflation and respiratory muscle interaction. Eur Respir J 1997; 10: 934-941. 
The loss of lung recoil displaces the pressure-volume $(P-V)$ relationship of the lung to the left, thus increasing $V \mathrm{r}$ if the chest wall elastic recoil remains unchanged, as is often the case in COPD patients [8]. At high lung volume, namely above $55 \%$ of vital capacity (VC) [1], the chest wall recoils inward (rather than outward, as occurs at normal FRC) such that pleural pressure remains positive throughout tidal expiration. Due to the loss of support determined by the destruction of the alveolar walls [9], small airways may be dynamically compressed during expiration by the positive pleural pressure, and can close earlier than normal, thus increasing the amount of air that is trapped in the lungs at the end of tidal expiration. This phenomenon is referred to as "air-trapping" and contributes to the increase in FRC [3].

The loss of lung recoil reduces the driving pressure for expiratory flow, which is also retarded by abnormal airway resistance due to inflammatory changes in the bronchial wall, mucus in the lumen, or smooth muscle contraction [10]. The association of: 1) loss of driving pressure; 2) dynamic compression of the small airways; and 3) reduced bronchial calibre can give rise to expiratory flow limitation during tidal breathing, which is a well-recognized condition in patients with advanced COPD [3, 4]. Under those circumstances, expiration cannot be completed within the time available, and inspiration starts before the lungs are fully decomposed, such that FRC stabilizes above $V_{\mathrm{r}}$ [11].

Expiratory flow may also be retarded by other mechanisms, such as increased post-inspiratory inspiratory muscle activity (PIIA) and narrowing of the glottis during expiration $[7,8]$. These events, associated with tachypnoea, represent a common mechanism to maintain FRC in order to improve airway patency and ventilation distribution in infants [12].

Dynamic pulmonary hyperinflation may also be determined by modifications in the timing of respiration. Indeed, a short expiratory duration $(t \mathrm{E})$, determined by an increased respiratory frequency $(f R)$ or a long inspiratory time $(t \mathrm{I})$ to total respiratory cycle duration ( $t$ tot) ratio $(t \mathrm{t} / t \mathrm{tot})$, i.e. duty cycle, may prevent complete decompression of the lungs $[2,13]$. The causes of pulmonary hyperinflation are summarized in table 1 .

\section{Consequences of pulmonary hyperinflation}

The pathophysiological effects of pulmonary hyperinflation are multiple and complex in nature. Although some potentially beneficial consequences cannot be ignored, the detrimental effects of pulmonary hyperinflation on lung and chest wall mechanics can totally overwhelm the potential benefits. The increase in lung volume may have a beneficial impact on lung mechanics by increasing airway patency. This, in turn, reduces

Table 1. - Causes of pulmonary hyperinflation

Loss of lung elastic recoil

Air-trapping

Expiratory flow limitation

Increased airflow resistance

Postinspiratory activity

Short expiratory time: increased $f \mathrm{R}$, increased $t \mathrm{I} / t_{\text {tot }}$

$f \mathrm{R}$ : respiratory frequency; $t \mathrm{t} / \mathrm{ttot}$ inspiratory time to total respiratory cycle duration, i.e. duty cycle. airway resistance and decreases the work of breathing, improves the distribution of ventilation and allows an increase in minute ventilation $\left(V^{\prime} \mathrm{E}\right)$ in patients who are using maximal expiratory flow during breathing at rest [14]. In addition, the displacement of tidal breathing toward the upper flat portion of the total respiratory system $P-V$ curve may increase the driving pressure for expiration and, hence, improve the rate of lung emptying. However, this upward movement of lung volume brings tidal breathing to the section of the $P-V$ curve where the chest wall recoils inward [1], thus increasing the elastic work of breathing because not only are the lungs in their less compliant portion but the chest wall must also be expanded. In addition, the inward chest wall recoil at high lung volume increases tidal expiratory flow limitation, as mentioned previously [15].

Pulmonary hyperinflation can profoundly alter the capacity of the inspiratory muscles to generate pressure both for length-tension reasons and geometric arrangement $[16,17]$, as has been examined by other articles in this series.

An additional major consequence of dynamic pulmonary hyperinflation is the development of intrinsic positive end-expiratory pressure (PEEPi), i.e. a positive end-expiratory alveolar pressure due to incomplete expiration [18-20]. PEEPi has important implications for the dynamics of breathing. Under normal circumstances, the ventilatory load on the respiratory muscles is made up of three types of resistance to motion: 1) the elastic resistance of lung and chest wall tissues when a change of volume occurs; 2) the frictional resistance to flow offered by the airways and the nonelastic deformation of tissue; and 3) the inertial forces, which depend on the mass of tissue and gas and are usually small enough to be neglected during tidal breathing [21, 22]. When there is no distortion of the respiratory system from its configuration during relaxation, the dynamics of breathing can be represented by a simple equation of motion using a model in which a rigid pipe ends in a compliant balloon [23]:

$$
P \text { mus }=P \text { el }+P \text { res }
$$

where $P$ mus is the pressure applied to the respiratory system by the contracting inspiratory muscles, and $P$ el and $P$ res are the pressures required to overcome the opposing elastic forces and to generate flow in the tubes, respectively. Assuming that the $P-V$ relationship is linear in the tidal volume $(V \mathrm{~T})$ range and that the resistive properties of the conducting airway are well described by Röhrer's equation, the equation of motion becomes:

$$
P \text { mus }=(V \mathrm{~T} / C \mathrm{rs})+\left(\mathrm{K} 1 V^{\prime}+\mathrm{K} 2 V^{\prime 2}\right)
$$

where $C$ rs is the compliance of the respiratory system, $V^{\prime}$ is ventilatory flow, and $\mathrm{K} 1$ and $\mathrm{K} 2$ are constants.

This equation is valid, provided that inspiration starts from $V$ r. If FRC is above $V \mathrm{r}$, as occurs during dynamic pulmonary hyperinflation, and the end-expiratory alveolar pressure is positive because of PEEPi, the equation becomes:

$$
P \text { mus }=\mathrm{PEEPi}+(V \mathrm{~T} / C \mathrm{rs})+\left(\mathrm{K} 1 V^{\prime}+\mathrm{K} 2 V^{\prime 2}\right)
$$

In fact, PEEPi, i.e. the end-expiratory $P$ el, represents the inspiratory threshold load, which must be fully counterbalanced by the contracting inspiratory muscles 
before a negative pressure can be created in the central airway to generate inspiratory flow. Clearly, the impact of PEEPi on the energetics of breathing will depend on its magnitude, which can be related to the amount of dynamic hyperinflation. However, if the $P-V$ curve is nonlinear at a lung volume below the dynamic FRC level, approaching $V \mathrm{r}$, PEEPi may be greater than the value predicted on the basis of the dynamic increase in lung volume. Another factor that has to be taken into account is the expiratory muscle activity, which can determine a positive end-expiratory alveolar pressure in the absence of dynamic pulmonary hyperinflation or can contribute to PEEPi [24]. It has been shown that the expiratory muscles are active during expiration in patients with stable [25] and exacerbated COPD [26-28], and that a variable portion of PEEPi may be due to active expiration rather than to incomplete lung emptying. This issue will be reconsidered in the section dedicated to measurement.

Pulmonary hyperinflation also has important cardiovascular consequences, which have recently been reviewed [29]. Briefly, large changes in intrathoracic pressures during the respiratory cycle profoundly affect venous return, right cardiac function, and cardiac output in general. The heart and the large vessels are contained within a thoracic compartment that senses pleural pressure as its surrounding pressure. Pleural pressure varies with ventilation and ventilatory manoeuvres whereas pulmonary vascular resistance varies with changes in lung volume. Thus, the heart is in an environment of ever changing pressures and resistances, independent of any measurable change in systemic arterial pressure. The salient factors that determine heart-lung interactions are: 1) changes in intrathoracic pressure, which modulate right atrial pressure and alter the pressure gradient for venous return; 2) the common interventricular septum and the pericardium, which directly affect the perceived biventricular diastolic compliance by the effect that the end-diastolic pressure of one ventricle exerts on the other; 3) changes in lung volume, which directly affect resistance to pulmonary blood flow and alter systolic pulmonary arterial pressure; and 4) changes in the intrathoracic pressure, which alter transmural aortic pressure and affect left ventricular systolic pressure load. Under all conditions, hyperinflation impairs right ventricular (RV) ejection, and often decreases cardiac output, both by impeding RV ejection and by decreasing systemic venous return. The major mechanical consequences of pulmonary hyperinflation are summarized in table 2 .

Table 2. - Consequences of dynamic hyperinflation

Changes in lung mechanics

Improved airway patency

Increased lung recoil

Increased elastic work of breathing

Inspiratory threshold load (PEEPi)

Decreased venous return and cardiac output

Decreased respiratory muscle pressure generating capacity Decreased operational length

Impaired geometric arrangement
Pulmonary hyperinflation in patients with airflow obstruction

COPD. Several measurements have shown that a slight degree of dynamic hyperinflation and PEEPi exist in COPD patients under stable conditions [30-33]. In acute exacerbations of COPD [3, 34, 35], airflow resistance increases because of airway inflammation due, for instance, to respiratory tract infections $[35,36]$. This imposes a substantial resistive load on the respiratory muscles, and also further slows the rate of lung emptying, conceivably by increasing the amount of dynamic pulmonary hyperinflation and PEEPi; on average, PEEPi increases from a few $\mathrm{cmH}_{2} \mathrm{O}$ to higher values [37]. The workload on the respiratory muscles increases due to high flow resistance and high PEEPi $[38,39]$, and the pressure generating capacity of the respiratory muscles is remarkably challenged by the abrupt dynamic increase in lung volume [40] and by a reduction in blood flow to the respiratory muscle [41]. The breathing pattern becomes rapid and shallow (fig. 1) as a result of

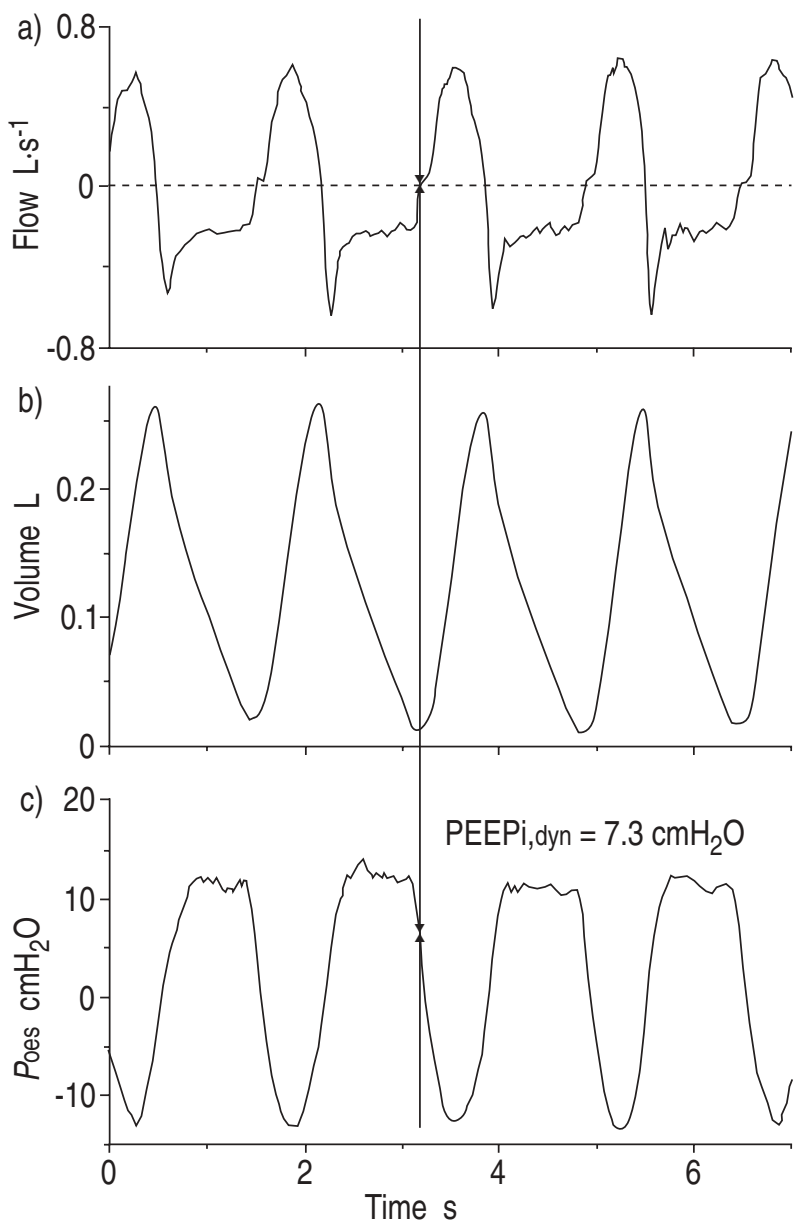

Fig. 1. - a) ventilatory flow; b) volume, and c) oesophageal pressure $\left(P_{\text {oes }}\right)$, in an intubated, spontaneously breathing patient with acute exacerbation of chronic obstructive pulmonary disease (COPD). The expiratory flow is abruptly stopped at end-expiration, whilst $P$ oes swing (namely the inspiratory effort) has already begun. The difference between the point corresponding to the onset of the change in $P_{\text {oes }}$ and the point of zero flow on the $P$ oes tracing, represents dynamic positive end-expiratory pressure (PEEPi,dyn), which has to be counterbalanced by the contracting inspiratory muscles in order to start inspiration. In this patient, the inspiratory muscles have to develop a pressure of $7.3 \mathrm{cmH}_{2} \mathrm{O}$ before the inspiratory flow can start. Tidal volume $(V \mathrm{~T})$ was $0.3 \mathrm{~L}$, respiratory frequency $(f \mathrm{R})$ was 35 breaths $\cdot \mathrm{min}^{-1}$, and minute ventilation $\left(V^{\prime} \mathrm{E}\right)$ was $10.5 \mathrm{~L} \cdot \mathrm{min}^{-1}$. 
stimulation of the irritant receptors and of the mechanical constraint due to the nonlinearity of the respiratory system $P-V$ curve at high lung volume. Moreover, the respiratory muscles are operating at less than optimal length [34, 35]. However, in view of the relationship:

$$
P \mathrm{a}, \mathrm{CO}_{2}=\mathrm{K} \times V^{\prime} \mathrm{CO}_{2} / V^{\prime} \mathrm{E}(1-V \mathrm{D} / V \mathrm{~T})
$$

(where $\mathrm{Pa}, \mathrm{CO}_{2}$ is arterial carbon dioxide tension, $V^{\prime} \mathrm{CO}_{2}$ is carbon dioxide elimination, and $V \mathrm{D} / V \mathrm{~T}$ is physiological dead space/tidal volume ratio) the rapid shallow breathing is a very poor compensatory mechanism, since the low $V \mathrm{~T}$, in patients with an abnormal $V \mathrm{D}$, can lead to progressive hypercapnia. This would require mechanical ventilation to support alveolar ventilation, to unload the respiratory muscles, and to prevent excessive deterioration in arterial blood gas tensions and $\mathrm{pH}$ [42].

Asthma. An increase in lung volumes is usually observed during an acute attack of asthma [43, 44]. The residual volume (RV) can increase because of gas-trapping due to premature airway closure [45], while $V \mathrm{r}$ has been found to increase significantly because of changes in the position of the $P-V$ curve of the lung [46]. The increase in FRC is also due to the sudden and marked increase in airflow resistance, due to intense airway smooth muscle contraction, mucous plugging in the bronchial lumen, and inflammatory infiltration of the bronchial wall [47, 48]. Studies during induced bronchoconstriction have suggested that increased postinspiratory activity of the inspiratory intercostal muscles (PIIA) could also play a role in the determination of pulmonary hyperinflation in asthma [49]. Pulmonary vascular resistance and, therefore, right ventricular afterload are increased because of hyperinflation, increased transmural pressure, and reflex vasoconstriction secondary to alveolar hypoxia and acidosis.

\section{Pulmonary hyperinflation and mechanical ventilation}

In mechanically ventilated patients, the mechanisms leading to pulmonary hyperinflation do not differ substantially from those described in spontaneously breathing patients, namely the loss of elastic recoil, an increased airflow resistance and a short expiratory time. However, there are some specific issues which should be taken into account, namely, the effect of the endotracheal tube and the mode and setting of the ventilator.

Effect of the endotracheal tube. Mechanical ventilation is usually delivered through an endotracheal tube, bypassing the compliant region of the upper airway. The endotracheal tube is stiff, such that the total elastic opposing forces to lung expansion are not basically affected. In contrast, the endotracheal tubes provide a substantial flow resistance, which increases with increasing flow, as illustrated in figure 2 . An additional resistance is provided by ventilator tubings, circuits, and devices, such as the positive end-expiratory pressure (PEEP) valve [50]. Therefore, the pressure necessary to overcome total flow resistance is substantially greater in intubated mechanically ventilated patients than in patients breathing spontaneously through an intact upper airway. Clearly, the additional flow resistance provided by narrow bore endotracheal tubes and ventilator circuits, together with the patient's airway resistance, contributes significantly to slow lung emptying $[50,51]$. For instance, dynamic pulmonary hyperinflation and PEEPi may occur not only in patients with asthma and exacerbated COPD, but also in ventilator-dependent patients without airway diseases, and even in patients with acute respiratory distress syndrome (ARDS), despite the fact that in these patients the low compliance provides a high driving pressure for expiration [7, 52].

Mode and setting of the ventilator. The magnitude of dynamic hyperinflation and PEEPi may depend heavily on the ventilator setting, namely $V \mathrm{~T}, f \mathrm{R}$ and inspiratory to expiratory time ratio (I:E). For instance, a large $V$ T requires a long $t \mathrm{E}$, which may not be compatible with the targeted arterial blood gas tensions, and expiration remains incomplete, being stopped by the next mechanical inflation before full decompression of the lung (fig. 3).

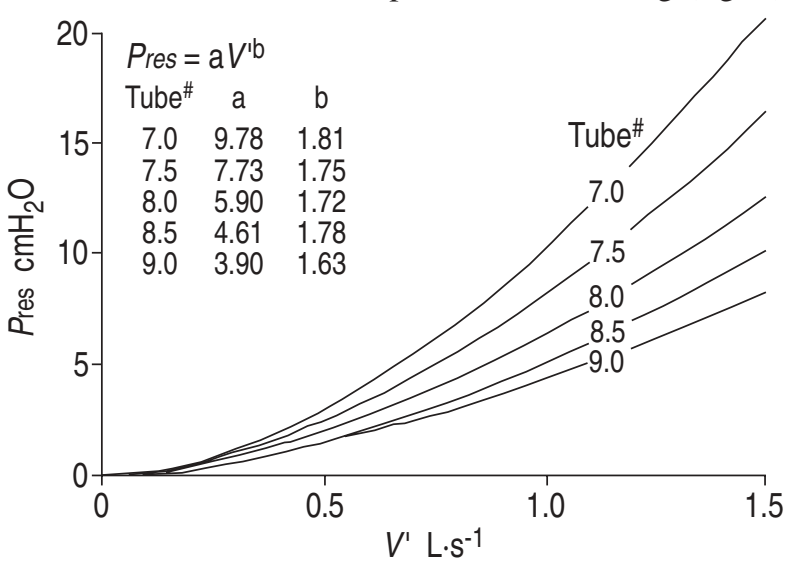

Fig. 2. - The relationship between resistive pressure (Pres) and air flow $\left(V^{\prime}\right)$ for endotracheal tubes (and connectors) of representative sizes. Also indicated are the results obtained by fitting measurements to a power function of the form $P$ res $=\mathrm{a} V^{\prime} \mathrm{b}$, where $\mathrm{a}$ and $\mathrm{b}$ are constants.

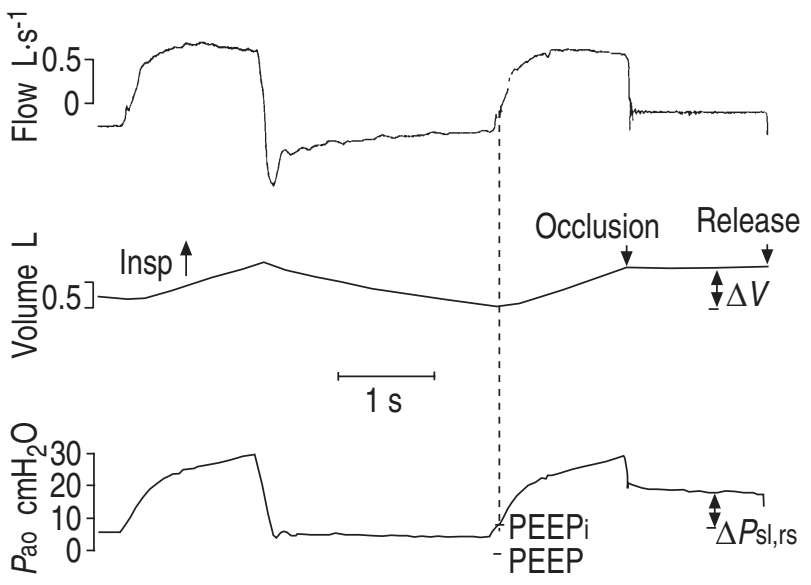

Fig. 3. - Tracings of ventilatory flow, volume and pressure at the airway opening $(P \mathrm{ao})$ in a mechanically ventilated patient with chronic obstructive pulmonary disease (COPD), at a positive end-expiratory pressure (PEEP) of $5.5 \mathrm{cmH}_{2} \mathrm{O}$. In this patient, expiratory flow continues throughout expiration, and the end-expiratory pause is replaced by a sudden reverse of flow from expiration to inspiration. Note also that inspiratory flow starts only after a pressure change of +4.5 $\mathrm{cmH}_{2} \mathrm{O}$ has been applied by the ventilator, as indicated by the vertical dashed line. This pressure is required to overcome the end-expiratory elastic recoil and is termed dynamic intrinsic positive end-expiratory pressure (PEEPi,dyn). $\Delta P$ el,rs: change in elastic recoil pressure of the respiratory system; Insp: inspiration. 

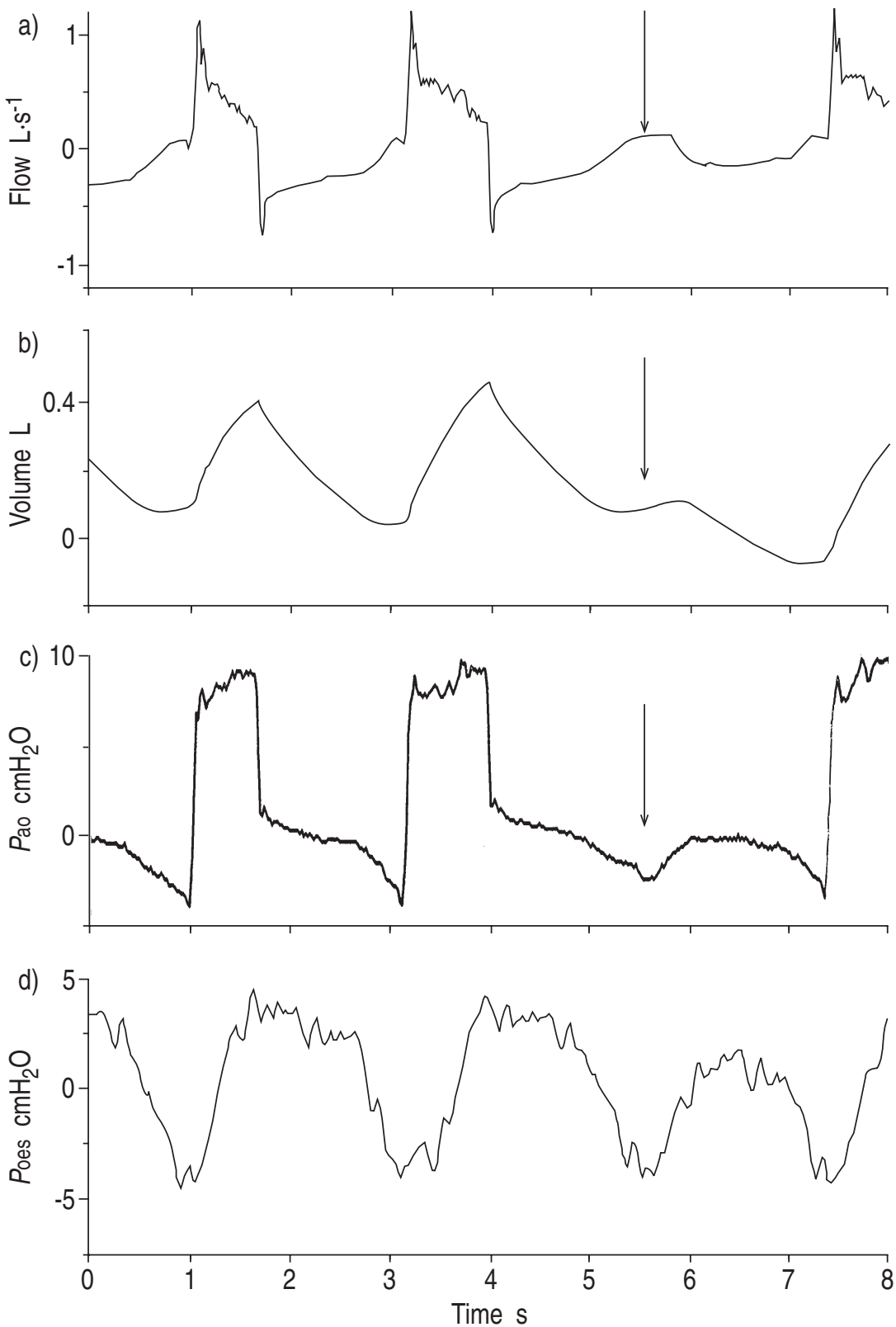

Fig. 4. - Records of: a) ventilatory flow; b) volume; c) pressure at the airway opening (Pao); and $\mathrm{d}$ ) oesophageal pressure $\left(P_{\mathrm{oes}}\right)$ in a ventilator-dependent patient during pressure support. The third inspiratory effort (arrow), as indicated by the negative swing in Poes, was not able to trigger the pressure boost. The ineffective efforts can be detected by the deflection on the flow and volume record and by the small decrease in $P$ ao.

In some patients with severe airway disease, even a long $t$ E, approaching $30 \mathrm{~s}$, may not be sufficient to complete expiration [52]. A high $f \mathrm{R}$ reduces the time available for exhalation and favours dynamic hyperinflation. Likewise, a long $t$ I with a low inspiratory flow ( $V$ 'I) also shortens $t \mathrm{E}$ and may cause a dynamic increase in EELV and PEEPi [7].

Involvement of dynamic hyperinflation and PEEPi may depend on the mode of mechanical ventilation.

Controlled mechanical ventilation $(C M V)$. During $\mathrm{CMV}$, the pressure to inflate the lungs is provided by the ventilator, such that PEEPi has no impact on the energetics of breathing. However, high levels of PEEPi impair cardiac filling and reduce cardiac output, syste- mic blood pressure and oxygen transport $[18,29]$. Furthermore, the dynamic hyperinflation associated with large $V \mathrm{~T}$ may unduly raise the end-inflation pressure, enhancing the risk of alveolar distension and disruption (barotrauma), particularly in patients with acute exacerbation of COPD [53] or asthma [54, 55].

A special mode of controlled ventilation is the mechanical ventilation with inverse ratio (IRV), i.e. a longer than usual $t$ I and low $V$ 'I, followed by a short $t \mathrm{E}$. It has been claimed that IRV can improve oxygenation in patients with severe hypoxaemia refractory to conventional ventilation and PEEP, by producing a lower peak cycling pressure $(P$ peak $)$ and using less PEEP than during conventional mechanical ventilation. Although it has not been taken into adequate account for long [56], the short $t \mathrm{E}$ of the IRV setting is of necessity associated with a dynamic increase in the EELV and PEEPi. The presence of PEEPi and the related rise in mean airway pressure can explain the observed improvements in arterial oxygen tension $\left(\mathrm{Pa}_{\mathrm{a}} \mathrm{O}_{2}\right)$ as well as the drop in cardiac output [57]. Because some level of PEEPi already exists, less PEEP is required to raise the $P \mathrm{a}, \mathrm{O}_{2}$ as compared to CMV [58]. It has been suggested that there is a lower risk of barotrauma using IRV, but this has not yet been proved. Furthermore, recent studies [27] have questioned the benefits of IRV on oxygenation.

Assisted mechanical ventilation (AMV). During assisted modes of mechanical ventilation, such as assist/control ventilation (ACV), synchronized intermittent mandatory ventilation (SIMV), and pressure support ventilation (PSV), PEEPi influences the dynamics of breathing. In general, the pressure threshold to trigger the mechanical breath is set at -1 to $-2 \mathrm{cmH}_{2} \mathrm{O}$, requiring only a small effort by the patient. If PEEPi is present and acts as an inspiratory threshold load, it adds to the triggering pressure, such that the total amount of effort needed for the patient to trigger the ventilator is made up of the small triggering pressure plus PEEPi. Clearly, high levels of PEEPi severely increase the magnitude of the total inspiratory effort needed for the patient to trigger the ventilator. In some instances, the negative pressure in the pleural swing generated by the contracting inspiratory muscles may even be smaller than PEEPi, and hence insufficient to trigger the ventilator, making the inspiratory effort ineffective [59] (fig. 4). Under those circumstances, i.e. great inspiratory effort to trigger the ventilator and ineffective efforts, mechanical ventilation 
may fail to achieve one of its major goals, namely to rest the patient's inspiratory muscles, which continue to contract under load. Discontinuation of mechanical support becomes difficult and the weaning procedure may be hampered $[59,60]$.

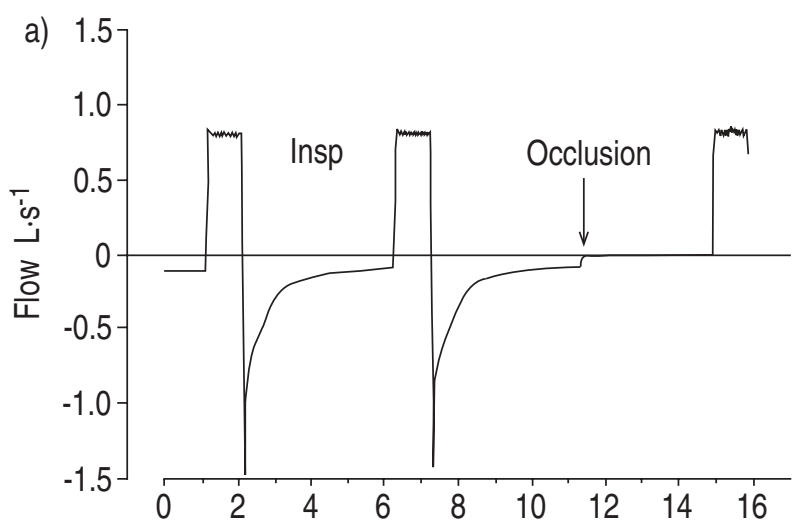

b) 1.0

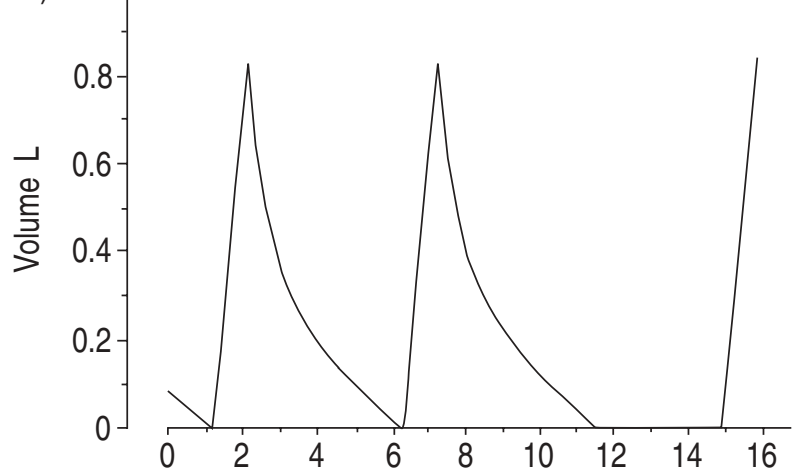

c) 60

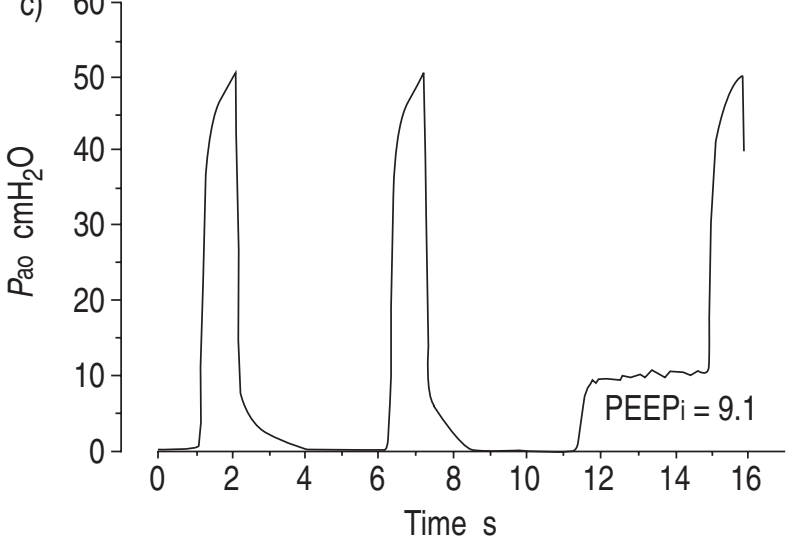

Fig. 5. - Representative record with measurement of intrinsic positive end-expiratory pressure (PEEPi) by end-expiratory airway occlusion (EEO) in a mechanically ventilated patient with acute exacerbation of chronic obstructive pulmonary disease (COPD) during controlled ventilation with constant inspiratory flow. Records of: a) ventilatory flow; b) volume; and c) pressure at the airway opening $(P$ ao $)$. Inspiration is upward. The horizontal line in the upper panel indicates zero flow. The first mechanical inflation is regular, namely without EEO: endexpiratory pressure is apparently atmospheric. In contrast, at the end of the second tidal expiration, the expiratory circuit of the $900 \mathrm{C}$ Siemens ventilator is occluded, using the end-expiratory hold button of the ventilator, and $P$ ao becomes positive, reflecting the end-expiratory elastic recoil of the respiratory system due to incomplete expiration. The value of PEEPi is provided by the difference between the EEO $P$ ao plateau and atmospheric pressure. Visual detection of the plateau on $P$ ao provides direct evidence of absence of leaks in the circuits, respiratory muscle relaxation, and equilibration between alveolar and tracheal pressure. Insp: inspiration.
Measurement of dynamic hyperinflation and PEEP $i$ in ventilator-dependent patients

Dynamic pulmonary hyperinflation and PEEPi must first be suspected, even if not quantified, from the shape of the end-expiratory flow, i.e. the lack of an end-expiratory pause in the flow-time record (fig. 5), and the presence of end-expiratory flow in the flow-volume curve (fig. 6).

The magnitude of dynamic pulmonary hyperinflation and PEEPi can easily be measured in ventilator-dependent patients during a complete relaxed expiration, as illustrated in figure 7 , and by means of end-expiratory occlusion, as illustrated in figure 5. Some values of change in functional residual capacity $(\triangle \mathrm{FRC})$ and of PEEPi in ventilator-dependent patients are reported in table 3 .

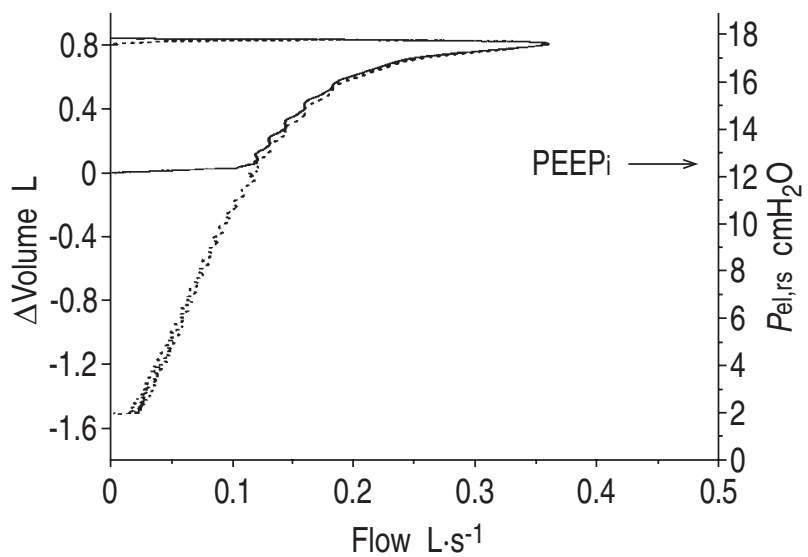

Fig. 6. - Relaxed expiratory volume-flow curves in a mechanically ventilated patient with acute exacerbation of chronic obstructive pulmonary disease (COPD) during controlled ventilation. - - tidal expiration; - - - - : an attempt at complete expiration to the relaxation volume, which, however, was not achieved. At the end of the tidal expiration, flow is suddenly stopped by the next mechanical lung inflation, indicating dynamic pulmonary hyperinflation. The volume axis (extrapolated to zero) was transformed into a pressure axis (right ordinate) by dividing volume $(V)$ by respiratory compliance according to the formula: $P$ el,rs $=V / C \mathrm{rs}$, where $P$ el,rs is the elastic recoil pressure of the respiratory system, and $C \mathrm{rs}$ is the respiratory compliance calculated by the interrupter technique. Dynamic hyperinflation, i.e. the difference between the relaxed volume and the tidal expired volume, amounted to $>1.5 \mathrm{~L}$ with a corresponding intrinsic positive end-expiratory pressure (PEEPi) amounting to $>12 \mathrm{cmH}_{2} \mathrm{O}$.

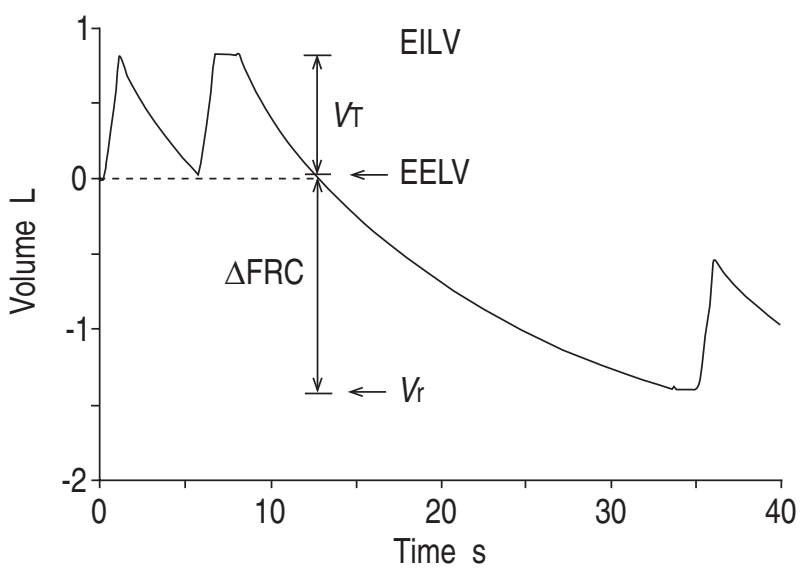

Fig. 7. - Volume-time relationship with a complete relaxed expiration following a brief end-inspiratory occlusion in a ventilator-dependent patient. EILV: end-inspiratory lung volume; VT: tidal volume; EELV: end-expiratory lung volume; $\triangle \mathrm{FRC}$ : difference in volume from EELV to the relaxed functional residual capacity (FRC), or relaxation volume $(V \mathrm{r})$. 
Table 3. - Values of intrinsic positive end-expiratory pressure $\left(P E E P_{i}\right)$, measured as illustrated in figure 7 , and of change in functional residual capacity $(\triangle F R C)$, measured as illustrated in figure 5 , in ventilator-dependent patients with COPD or asthma

\begin{tabular}{rcl}
\hline [Ref.] & PEEPi $\mathrm{cmH}_{2} \mathrm{O}$ & $\Delta$ FRC L \\
\hline$[7]$ & $11.5 \pm 3.1$ & $0.53 \pm 0.26$ \\
{$[40]$} & $12.0 \pm 0.4$ & $0.93 \pm 0.07$ \\
{$[52]$} & $13.6 \pm 6.7$ & $0.66 \pm 0.02$ \\
{$[61]$} & $5.1 \pm 0.3$ & - \\
{$[62]$} & $4.6 \pm 0.9$ & $0.42 \pm 0.18$ \\
{$[63]$} & $7.3 \pm 2.2$ & $0.60 \pm 0.46$ \\
{$[64]$} & $9.8 \pm 0.5$ & $0.91 \pm 0.99$ \\
{$[65]$} & $5.7 \pm 0.9$ & $0.34 \pm 0.06$
\end{tabular}

It has to be considered that values of PEEPi and $\triangle \mathrm{FRC}$ are dependent not only on patients' respiratory mechanics but also on the ventilator setting, i.e. $V \mathrm{~T}, t \mathrm{E}$, etc. COPD: chronic obstructive pulmonary disease, $V \mathrm{~T}$ : tidal volume; $t \mathrm{E}$ : expiratory time.

These measurements are more complicated in actively breathing subjects, for instance during assisted ventilation and weaning from mechanical ventilation. In fact, neither a complete relaxed expiration to $V_{\mathrm{r}}$ nor a plateau during the end-expiratory occlusion can be easily obtained in these subjects, and measurement of PEEPi may require the use of an oesophageal balloon to estimate changes in $P$ pl [20]. In this condition, dynamic intrinsic PEEP (PEEPi,dyn) is measured from the decrease in $P \mathrm{pl}$ preceding the onset of inspiratory flow, because PEEPi is offset first (fig. 1). However, if the expiratory muscles are contracting during expiration, the fall in $P$ pl preceding inspiration may be due to the

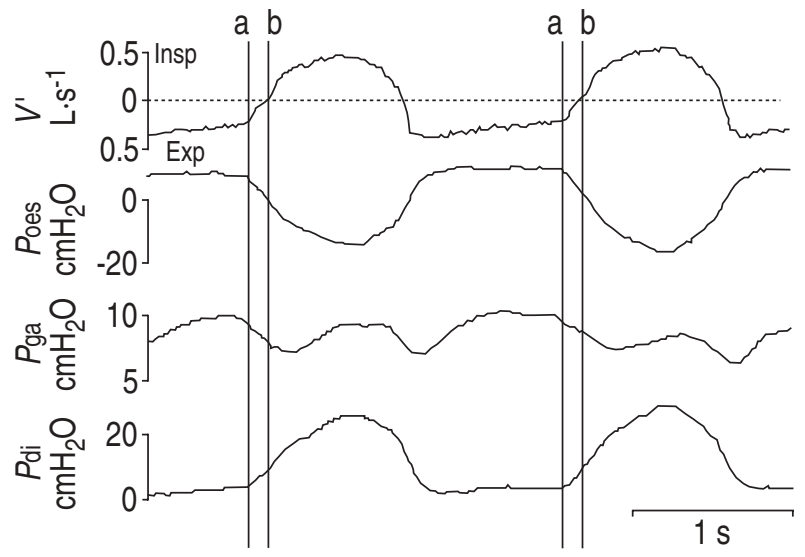

Fig. 8. - Experimental record illustrating the measurement of dynamic intrinsic positive end-expiratory pressure (PEEPi,dyn) from simultaneous recording of ventilatory flow and oesophageal pressure during spontaneous breathing in a representative patient showing evidence of expiratory muscle activity during an acute exacerbation of chronic obstructive pulmonary disease (COPD). Tracings represent: ventilatory flow $\left(V^{\prime}\right)$; oesophageal pressure $(P$ oes $)$; gastric pressure $(P$ ga $)$; and transdiaphragmatic pressure $(P \mathrm{di})$. The first vertical line $(a)$ indicates the point corresponding to the onset of the inspiratory effort $(P$ di swing). The second vertical line $(b)$ indicates the point corresponding to the start of inspiratory flow. The dotted horizontal line represents zero flow. Insp: inspiratory flow; Exp: expiratory flow. Tidal volume was $0.33 \mathrm{~L}$. Note that $P$ ga increased throughout most of the expiration. By contrast, $P$ ga became less positive from the onset of the inspiratory effort, indicated by the start of positive $P$ di swing to the start of inspiratory flow. In this case PEEPi,dyn was measured as the negative $P$ oes deflection between the point corresponding to the onset of $P$ di swing and the point of zero flow subtracted by the amount of $P$ ga negative deflection observed in that interval. (From [26], with permission). relaxation of the expiratory muscles rather than to contraction of the inspiratory muscles [24-27]. Nevertheless, it has been suggested that, in this condition, PEEPi can be measured by subtracting the decrease in gastric pressure $(P \mathrm{ga})$ from the decrease in $P$ pl from the onset of the inspiratory effort (indicated by the onset of the transdiaphragmatic pressure swing) to the point of zero flow (fig. 8) [26]. Other authors suggested subtracting the complete fall in $P$ ga [27].

This issue is still a matter of debate. In addition, it should be remembered that during measurement of PEEPi the diaphragmatic force of contraction can increase $P$ ga whilst the concomitant relaxation of the expiratory muscles decreases $P$ ga, such that the relative magnitude of these two separate events remains unpredictable. Furthermore, expiratory rib cage muscles can be active and also affect oesophageal pressure $\left(P_{\text {oes }}\right)$. Therefore, after correction for $P$ ga, the measurement of PEEPi,dyn from the decrease in $P$ oes preceding inspiration may not be fully satisfactory [28]. It is our opinion that the endexpiratory occlusion method of obtaining a plateau of airway pressure, and hence measuring PEEPi as the static end-expiratory recoil pressure, should also be used during ACV, SIMV and PSV.

\section{Treatment}

Clearly, the anatomical changes determining pulmonary hyperinflation, such as the loss of lung elastic recoil and small airways compression due to destruction of pulmonary tissue, are to a large extent irreversible. In contrast, some mechanisms underlying dynamic pulmonary hyperinflation, such as abnormal flow resistance and short expiratory duration, may be modified with pharmacological treatment or by changing the ventilator settings.

\section{Pharmacological treatment}

Bronchodilators. Bronchodilators are the most important medical therapy of pulmonary hyperinflation, because reduction of airflow resistance through bronchial smooth muscle relaxation improves the rate of lung emptying, thereby diminishing dynamic hyperinflation and PEEPi. As illustrated in figure 9, adrenaline i.v. produced a marked bronchodilatation associated with a decrease of PEEPi in a ventilator-dependent patient with acute severe asthma [66].

Beta $_{2}$-agonists are the bronchodilators of choice. Many studies [67-69] have shown that $\beta_{2}$-agonists cause a significant bronchodilatation in mechanically ventilated patients with COPD, and, hence, a reduction of pulmonary hyperinflation (fig. 10). However, some questions remain open regarding the optimal delivery of inhaled $\beta_{2}$-agonists in the critical care setting [69]. Recent data suggest that, in nonintubated asthmatic patients, metereddose inhalers (MDIs) combined with a spacing device are just as effective as nebulizers, and are quicker and cheaper to use [70]. In mechanically ventilated patients, there is a consensus that, whether MDIs or nebulizers are used, higher drug dosages are required to achieve a physiological effect than in nonintubated patients [70]. 


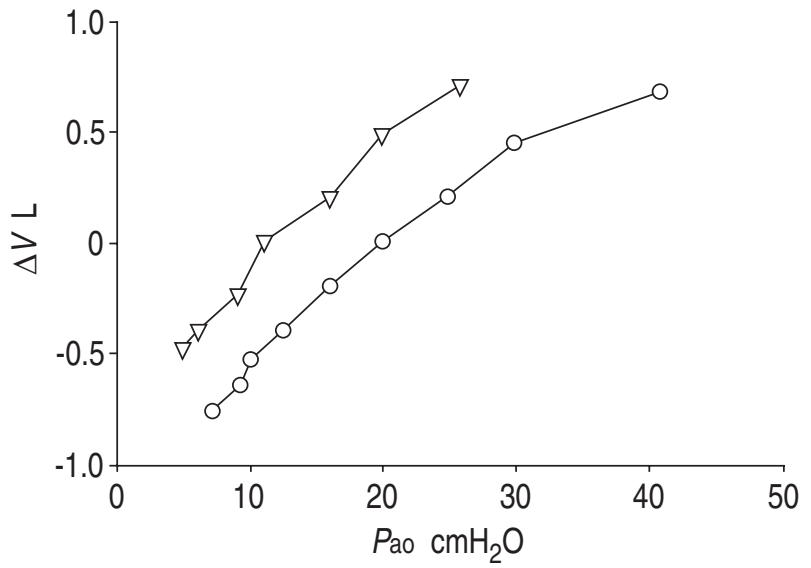

Fig. 9. - Static pressure-volume $(P-V)$ curves in a mechanically ventilated patient with acute severe asthma. Experimental points were obtained by the interrupter technique. - $\mathrm{O}-$ : interrupter measurements at baseline; $\rightarrow-$ - interrupter measurements after $0.1 \mathrm{mg}$ adrenaline. The relaxant effect of adrenaline on bronchial smooth muscle decreased both the amount of dynamic pulmonary hyperinflation and PEEPi, without changes in the slope of the $P-V$ curve, i.e. respiratory compliance. Although patients were allowed $30 \mathrm{~s}$ for breathing out, expiration was still not completed because of the extreme flow resistance and possibly expiratory flow limitation. Pao: pressure at airway opening; PEEPi: intrinsic positive end-expiratory pressure; $\Delta V$ : difference in volume.

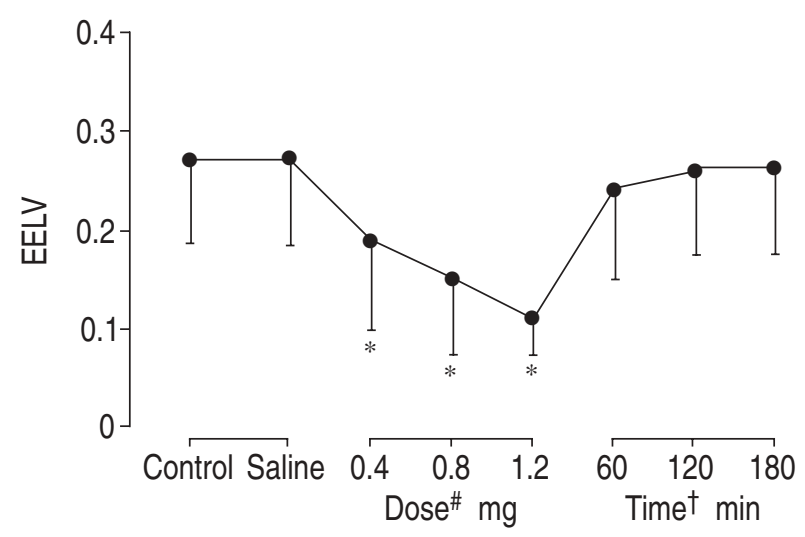

Fig. 10. - Effect of fenoterol on end-expiratory lung volume (EELV), in mechanically ventilated patients with acute exacerbation of chronic airflow obstruction. Values are presented as mean and SEM $(\mathrm{n}=7)$. *: analysis of variance (ANOVA) was significant $(\mathrm{p}<0.05)$, when all values were compared to control using the Wilcoxon's test for paired data. \#: cumulative dose of fenoterol aerosol; $\pitchfork$ : time since last dose of fenoterol. At the time of the study, the patients were receiving continuous amynophylline.

A recent study [69] has shown that, if a proper technique of delivery is used to avoid aerosol deposition in the endotracheal tube and ventilator circuit, MDI is an effective, convenient and safe method even with low doses (four puffs) of a sympathomimetic aerosol [71, 72]. BERnASCONi et al. [68] suggested that frequent administration of smaller doses of $\beta_{2}$-agonists might be preferable to occasional administration of larger doses.

Anticholinergics usually produce less bronchodilation than $\beta_{2}$-agonists in patients with acute asthma [73], but may be more effective in patients with COPD. Their use is recommended in COPD patients suffering from daily symptoms [73, 74]. In ventilator-dependent patients, the combination of a $\beta_{2}$-agonist with an anticholinergic was more effective than an anticholinergic alone to decrease airflow resistance [75].
There are no strong conclusions about the use of theophylline in acute asthma. Some authors have demonstrated that the addition of theophylline to $\beta_{2}$-agonists in the first hours of treatment does not confer additional benefit, whilst there is an increase of side-effects [76]. In mechanically ventilated patients with COPD, PoGGI et al. [76] have shown that doxophylline, a newer methylxanthine, can produce significant bronchodilatation. After an initial enthusiasm, the ability of theophylline to enhance respiratory muscle function and to improve the weaning process has not been conclusively demonstrated [77].

Corticosteroids. The benefits of steroids in the treatment of asthma are well known [73]. Some authors suggest that steroids given in the emergency room significantly reduce the rate of admissions and the number of future relapses in patients with acute asthma [70]. In COPD patients with acute exacerbation, a course of oral steroids [78] may be needed but the risks of side-effects, in particular steroid-induced myopathy [79], must be taken into account, especially in older patients [80]. However, in mechanically ventilated COPD patients, NAvA et al. [81] showed that a bolus of methylprednisolone given intravenously acutely decreased the respiratory resistance and PEEPi, and concluded that this drug may be used in combination with standard bronchodilators, or even alone, to improve bronchial patency.

Heliox. Heliox is a mixture of the gases helium and oxygen, with a density less than that of air. Breathing of heliox decreases airflow resistance in bronchi where flow is turbulent. Heliox has been used to reduce flow resistance in mechanically ventilated patients with acute bronchial asthma [70]. Furthermore, inhalational anaesthesia decreased flow resistance and hyperinflation in ventilator-dependent asthmatics [82].

\section{Ventilator setting}

In ventilator-dependent patients with airway diseases, the ventilatory pattern should be set so as to provide the longest expiratory phase compatible with the patient's comfort and adequate gas exchange. This can be achieved during controlled ventilation by decreasing $f \mathrm{R}$ and $t$ I or increasing $V^{\prime}$ I. At any given level of $V^{\prime} \mathrm{E}$, a rise in $V$ 'I will reduce $t \mathrm{I}$ and increase $t \mathrm{E}$, reducing the $t \mathrm{I} / t$ tot or the I:E ratio [37]. Traditionally, this approach has been discouraged, to prevent excessive increase in $P$ peak and to reduce the risk of barotrauma. However, $P$ peak is a poor indication of the risk of barotrauma, since it includes the resistive pressure dissipation in the endotracheal tube. A better approximation of alveolar pressure may be obtained from the value of the plateau pressure during the end-inspiratory occlusion [83]. In this connection, it should be mentioned that $5 \mathrm{~s}$ of airway occlusion are needed to reach the plateau of airway pressure, and, hence, to measure the static recoil pressure of the respiratory system at the occluded lung volume [83].

Controlled hypoventilation in asthma. The traditional view that a $\mathrm{Pa}_{\mathrm{a}} \mathrm{CO}_{2}$ higher than $6.0 \mathrm{kPa}(45 \mathrm{mmHg})$ is an adverse event in mechanically ventilated patients with 
asthma has been challenged by the work of PERRET and co-workers [84-86], who used "controlled hypoventilation" to improve the clinical outcome in patients with status asthmaticus. The use of lower than traditional inflation volume resulted in a dramatic drop in ventilator-induced barotrauma. Indeed, the lower $V \mathrm{~T}$ decreases the end-inflation pressure and PEEPi by reducing the amount of air to be exhaled. However, the reduction in $V^{\prime} \mathrm{E}$ and $V \mathrm{~T}$ decreases alveolar ventilation and, hence, determines a rise in $\mathrm{Pa}_{\mathrm{a}} \mathrm{CO}_{2}$, which has been called "permissive hypercapnia" [86].

The volume measured during a complete, or almost complete, relaxed expiration starting from end-inspiration has been termed $V \mathrm{EI}$ and includes both $V \mathrm{~T}$ and the volume exhaled from the tidal end-expiration to $V \mathrm{r}(V \mathrm{EE})$ (figs. 3 and 4). Williams et al. [54] suggested that measurement of $V$ EI could provide a useful guideline to prevent excessive pulmonary hyperinflation, resulting in a better clinical outcome. A value of $V \mathrm{EI}<20 \mathrm{~mL} \cdot \mathrm{kg}^{-1}$ was indicated as sufficiently safe to prevent incidence of barotrauma. Clearly, in the management of the individual patient, risks related to pulmonary hyperinflation on the one hand and to permissive hypercapnia on the other must be carefully evaluated. For example, purposeful hypoventilation is a strategy best avoided in patients with raised intracranial pressure and in patients with severely depressed myocardial function. It has been suggested that $P \mathrm{a}, \mathrm{CO}_{2}$ should not exceed $12.0 \mathrm{kPa}$ $(90 \mathrm{mmHg}$ ) [86], and that a $\mathrm{pH}<7.20$ should be treated with sodium bicarbonate [70].

PEEP and continuous positive airway pressure (CPAP). In mechanically ventilated patients with severe pulmonary hyperinflation, low levels of PEEP and CPAP have been applied to unload the respiratory muscles during assisted mechanical ventilation and weaning, respectively $[15,56,87]$. In fact, PEEP and CPAP counterbalance PEEPi and reduce the level of inspiratory effort needed either to trigger the mechanical breath or to sustain spontaneous ventilation. A recent study by APPENDINI et al. [26] has shown that low levels of PEEP significantly unload the inspiratory muscles during noninvasive mechanical ventilation and in tracheostomized ventilatordependent COPD at any given level of PSV. However, neither PEEP nor CPAP treat pulmonary hyperinflation, and levels higher than 5-7 $\mathrm{cmH}_{2} \mathrm{O}$ must be used with caution in order not to cause a further increase in lung volume. Furthermore, it should be taken into account that application of PEEP and CPAP does not increase lung volumes only in patients with expiratory flow limitation. This makes the assessment of expiratory flow limitation mandatory before PEEP and CPAP are applied.

As shown by figure 11 , the presence of expiratory flow limitation can be assessed by means of the negative expiratory pressure (NEP) technique recently developed by MiLic-EmiLi and co-workers [88-90]. Briefly, a small NEP of about $-5 \mathrm{cmH}_{2} \mathrm{O}$ can be applied at the airway opening during tidal expiration, such that the ensuing expiratory flow-volume curve is compared with the previous control expiration. As illustrated in figure 11 , expiratory flow increases with NEP in the absence of expiratory flow limitation, whereas in patients with expiratory flow limitation, expiratory flow does not increase with NEP, either throughout the tidal expiration a)
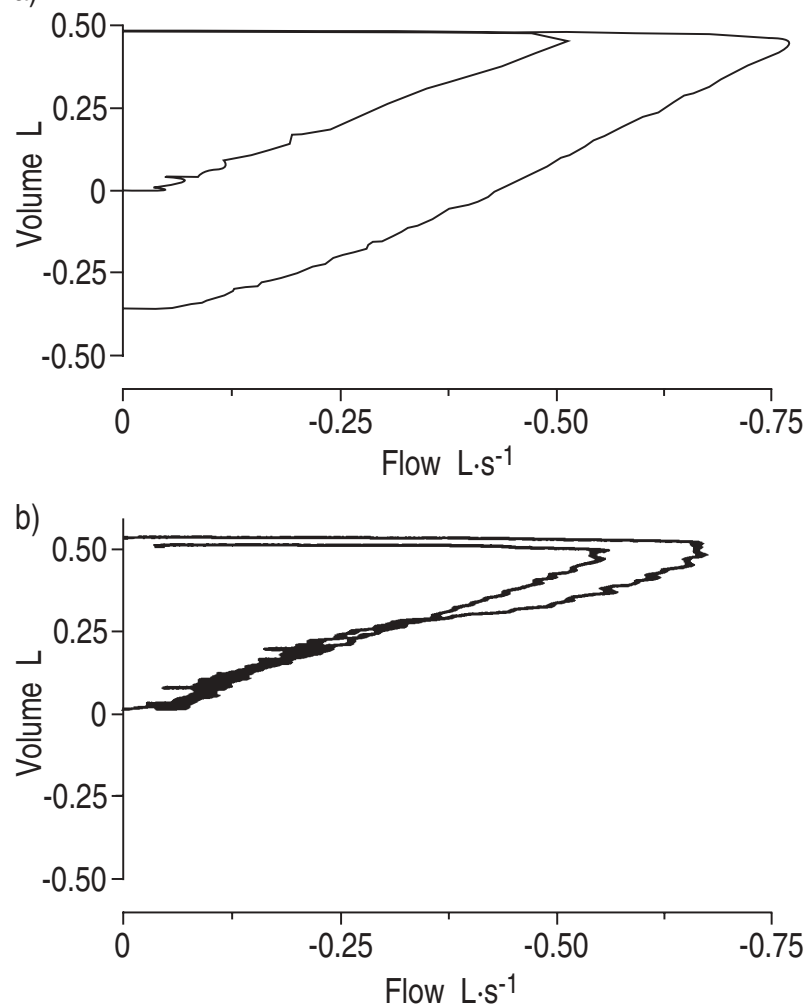

Fig. 11. - Effects of a negative expiratory pressure (NEP) on expiratory flow-volume curves: a) in a patient without flow limitation; and $b$ ) in a patient with flow limitation. In the latter, NEP does not increase flow in the second half of the expiration.

or for part of it, although a transient change may appear due to displacement of gas from the expiratory line for rapid decompression.

\section{Summary}

Pulmonary hyperinflation is a major medical problem, particularly in ventilator-dependent patients with exacerbated COPD or acute asthma. Apparent beneficial effects on lung mechanics, such as an increased airway patency and elastic recoil, are overwhelmed by the deleterious effects on the pressure generating capacity of respiratory muscles. Moreover, the ventilatory workload can be remarkably increased by the displacement of the respiratory system toward the upper, flat portion of the $P-V$ curve, by the need to expand the chest wall and not only the lungs, and by the PEEPi systematically associated with dynamic hyperinflation.

Pulmonary hyperinflation increases the risk of barotrauma and may hamper weaning due to the excessive burden of PEEPi which can even lead to ineffective inspiratory efforts. Because of its harmful consequences, the causes of pulmonary hyperinflation must be treated aggressively with bronchodilators and steroids whenever needed. In spontaneously breathing patients, the shallow and rapid breathing pattern may be controlled, in some instances, by reducing the patient's pain, fever and anxiety. In ventilator-dependent patients, the setting of the ventilator must be predetermined to ensure the longest possible time for expiration, and positive end- 
expiratory pressure can be applied to prevent an excessive workload for the patient and ineffective inspiratory efforts.

Acknowledgements: The authors wish to thank A. Ciucci and F. Guardini for help in preparing the manuscript.

\section{References}

1. Agostoni E, Mead J. Statics of the Respiratory System In: Fenn WO, Rahn H, eds. Handbook of Physiology. Washington DC, American Physiological Society, 1964; 1: pp. 387-409.

2. Vinegar A, Sinnett EE, Leith DE. Dynamic mechanisms determine functional residual capacity in mice, Mus musculus. J Appl Physiol: Respirat Environ Exercise Physiol 1979; 46: 867-871.

3. Pride NB, Milic-Emili J. Lung mechanics. In: Calverley P, Pride N, eds. Chronic Obstructive Pulmonary Disease. London, Chapman \& Hall, 1995; pp. 135-160.

4. Similowski T, Derenne JP, Milic-Emili J. Respiratory mechanics during acute respiratory failure of chronic obstructive pulmonary disease. In: Derenne JP, Whitelaw WA, Similowski T, eds. Acute Respiratory Failure in Chronic Obstructive Pulmonary Disease. New York, Dekker, 1996; 92: pp. 23-46.

5. Pride NB, Macklem PT. Lung mechanics in disease. In: Macklem PT, Mead J, eds. Handbook of Physiology. Section 3. The Respiratory System. Bethesda, American Physiological Society, 1986; 3: pp. 659-692.

6. Broseghini C, Brandolese R, Poggi R, et al. Respiratory resistance and intrinsic positive end-expiratory pressure $(\mathrm{PEEP} \mathrm{i})$ in patients with the adult respiratory distress syndrome (ARDS). Eur Respir J 1988; 1: 726-731.

7. Rossi A, Polese G, Brandi G. Dynamic hyperinflation. In: Marini JJ, Roussos C, eds. Ventilatory Failure. Berlin, Springer-Verlag, 1991; 15: pp. 199-218.

8. De Troyer A, Pride NB. The chest wall and respiratory muscles in chronic obstructive pulmonary disease. In: Roussos C, ed. The Thorax. New York, Dekker, 1995; 85: pp. 1975-2006.

9. Saetta M, Ghezzo H, Kim VD, et al. Loss of alveolar attachment in smokers. Am Rev Respir Dis 1985; 132: 894-900.

10. Lamb D. Pathology. In: Calverley P, Pride N, eds. Chronic Obstructive Pulmonary Disease. London, Chapman \& Hall, 1995; pp. 9-45.

11. Macklem PT. Hyperinflation. Am Rev Respir Dis 1984; 129: 1-2.

12. England SJ, Gaultier C, Bryan AC. Chest wall mechanics in the newborn. In: Roussos $\mathrm{C}$, ed. The Thorax. New York, Dekker, 1995; 85: pp. 1541-1555.

13. Mortola JP. Chest wall mechanics in newborns. In: Roussos C, ed. The Thorax. New York, Dekker, 1995; 85: pp. 617-631.

14. Ward ME, Roussos C, Macklem PT. Respiratory mechanics. In: Murray JF, Nadel JA, eds. Textbook of Respiratory Medicine. Philadelphia, Saunders, 1994; pp. 90-138.

15. Gottfried SB. The role of PEEP in the mechanically ventilated COPD patient. In: Marini JJ, Roussos C, eds. Ventilatory Failure. Berlin, Springer-Verlag, 1991; 15: pp. 392-418.

16. Decramer M, Derom E, Gosselink R. Respiratory muscle mechanics in chronic obstructive pulmonary disease and acute respiratory failure. In: Derenne JP, Whitelaw
WA, Similowski T, eds. Acute Respiratory Failure in Chronic Obstructive Pulmonary Disease. New York, Dekker, 1996; 92: pp. 47-64.

17. Decramer M, Macklem PT. Pressures developed by the respiratory muscles. In: Roussos $\mathrm{C}$, ed. The Thorax. New York, Dekker, 1995; pp. 1099-1126.

18. Pepe PE, Marini JJ. Occult positive end-expiratory pressure in mechanically-ventilated patients with airflow obstruction. Am Rev Respir Dis 1982; 126: 166-170.

19. Rossi A, Gottfried SB, Zocchi L, et al. Measurement of static compliance of the total respiratory system in patients with acute respiratory failure during mechanical ventilation: the effect of "intrinsic" PEEP. Am Rev Respir Dis 1985; 131: 672-767.

20. Rossi A, Polese G, Brandi G, Conti G. Intrinsic positive end-expiratory pressure $(\mathrm{PEEP} \mathrm{i})$. Intensive Care Med 1995; 21: 522-536.

21. Macklem PT. The act of breathing. In: Roussos C, ed. The Thorax. New York, Dekker, 1995; 85: pp. 445-456.

22. D'Angelo E, Milic-Emili J. Dynamics of the respiratory system. In: Roussos C, ed. The Thorax. New York, Dekker, 1995; 85: pp. 495-513.

23. Rodarte JR, Rehder K. Dynamics of respiration. In: Macklem PT, Mead J, eds. Handbook of Physiology. Section 3. The Respiratory System. Bethesda, American Physiological Society, 1986; 3: pp. 131-144.

24. Ninane V, Rypens F, Yernault JC, De Troyer A. Abdominal muscle use during breathing in patients with chronic airflow obstruction. Am Rev Respir Dis 1992; 146: 16-21.

25. Ninane V, Yernault JC, De Troyer A. Intrinsic PEEP in patients with chronic obstructive pulmonary disease. Am Rev Respir Dis 1993; 148: 1037-1042.

26. Appendini L, Patessio A, Zanaboni S, et al. Physiologic effects of positive end-expiratory pressure and mask pressure support during exacerbations of chronic obstructive pulmonary disease. Am J Respir Crit Care Med 1994; 149: 1069-1076.

27. Lessard MR, Lofaso F, Brochard L. Expiratory muscle activity increases intrinsic positive end-expiratory pressure independently of dynamic hyperinflation in mechanically-ventilated patients. Am J Respir Crit Care Med 1995; 151: 562-569.

28. Yan S, Kayser B, Tobiasz M, Sliwinsky P. Comparison of static and dynamic intrinsic positive end-expiratory pressure using the Campbell diagram. Am J Respir Crit Care Med 1996; 154: 938-944.

29. Ranieri VM, Dambrosio M, Brienza N. Intrinsic PEEP and cardiopulmonary interaction in patients with COPD and acute ventilatory failure. Eur Respir $J$ 1996; 9: 1283-1292.

30. Dal Vecchio L, Polese G, Poggi R, Rossi A. "Intrinsic" positive end-expiratory pressure in stable patients with chronic obstructive pulmonary disease. Eur Respir $J$ 1990; 3: 74-80.

31. Haluszka J, Chartrand DA, Grassino A, Milic-Emili J. Intrinsic PEEP and arterial $P_{\mathrm{CO}_{2}}$ in stable patients with chronic obstructive pulmonary disease. Am Rev Respir Dis 1990; 141: 1194-1197.

32. Begin P, Grassino A. Inspiratory muscle dysfunction and chronic hypercapnia in chronic obstructive pulmonary disease. Am Rev Respir Dis 1991; 143: 905-912.

33. Aldrich TK, Hendler JM, Vizioli LD, Park M, Multz AS, Shapiro SM. Intrinsic positive end-expiratory pressure in ambulatory patients with airway obstruction. Am Rev Respir Dis 1993; 147: 845-849.

34. Rossi A, Polese G, De Sandre G. Respiratory failure 
in chronic airflow obstruction: recent advances and therapeutic implications in the critically ill patient. Eur $J$ Med 1992; 1: 349-357.

35. ERS Consensus Statement. Optimal assessment and management of chronic obstructive pulmonary disease (COPD). Eur Respir J 1995; 8: 1398-1420.

36. ATS Statement. Standards for the diagnosis and care of patients with chronic obstructive pulmonary disease. Am J Respir Crit Care Med 1995; 152: S77-S120.

37. Rossi A, Polese G, Milic-Emili J. Mechanical ventilation in the passive patient: theory and clinical investigation. In: Derenne JP, Whitelaw WA, Similowski T, eds. Acute Respiratory Failure in Chronic Obstructive Pulmonary Disease. New York, Dekker, 1996; 92: pp. 709-746.

38. Appendini L, Purro A, Patessio A, et al. Partitioning of inspiratory muscle workload and pressure assistance in ventilator-dependent COPD patients. Am J Respir Crit Care Med 1996; 154: 1301-1309.

39. Ranieri VM, Grasso S, Mascia L, et al. Effects of proportional assist ventilation on inspiratory muscle effort in patients with chronic obstructive pulmonary disease and acute respiratory failure. Anesthesiology 1997; 86: 79-91.

40. Ranieri VM, Giuliani R, Mascia L, et al. Chest wall and lung contribution to the elastic properties of the respiratory system in patients with chronic obstructive pulmonary disease. Eur Respir J 1996; 9: 1232-1239.

41. Kawagoe Y, Permutt S, Fessler HE. Hyperinflation with intrinsic PEEP and respiratory muscle blood flow. J Appl Physiol 1994; 77: 2440-2448.

42. Slutsky AS. Mechanical ventilation. In: Crystal RG, West JB, eds. The Lung: Scientific Foundations. New York, Raven Press, 1991; 2: pp. 2163-2174.

43. Blackie SP, Al-Majed S, Staples CA, Hilliam C, Paré PD. Changes in total lung capacity during acute spontaneous asthma. Am Rev Respir Dis 1990; 142: 79-83.

44. Rossi A, Ganassini A. Near-fatal asthma and mechanical ventilation. Monaldi Arch Chest Dis 1996; 51: 99-101.

45. Cormier Y, Lecours R, Legris C. Mechanism of hyperinflation in asthma. Eur Respir J 1990; 3: 619-624.

46. Wheatley JR, West S, Cala SJ, Engel LA. The effect of hyperinflation on respiratory muscle work in acute induced asthma. Eur Respir J 1990; 3: 625-632.

47. James AJ, Paré PD, Hogg JC. The mechanism of airway narrowing in asthma. Am Rev Respir Dis 1989; 139: 242-246.

48. Djukanovic R, Roche WR, Wilson JW, et al. Mucosal inflammation in asthma. Am Rev Respir Dis 1990; 142: 434-457.

49. Martin JG, De Troyer A. The thorax and control of functional residual capacity. In: Roussos C, Macklem PT, eds. The Thorax. New York, Dekker, 1985; 29: pp. 899-921.

50. Marini JJ. Airway resistance, an old friend revisited. Intensive Care Med 1994; 20: 401-402.

51. Conti G, De Blasi RA, Lappa A, et al. Evaluation of respiratory system resistance in mechanically-ventilated patients: the role of the endotracheal tube. Intensive Care Med 1994; 20: 421-424.

52. Broseghini C, Brandolese R, Poggi R, et al. Respiratory mechanics during the first day of mechanical ventilation in patients with pulmonary edema and chronic airway obstruction. Am Rev Respir Dis 1988; 138: 355-361.

53. Bone RC. Monitoring ventilatory mechanics in acute respiratory failure. Respir Care 1983; 28: 597-603.

54. Williams TJ, Tuxen DV, Scheinkestel CD, Czarny D, Bowes G. Risk factors for morbidity in mechanically ventilated patients with acute severe asthma. Am Rev Respir Dis 1992; 146: 607-615.

55. Pingleton SK, Rossi A. Respiratory and nonrespiratory complications of critical illness. In: Parrillo JE, Bone RC, eds. Critical Care Medicine. Principles of Diagnosis and Management. St. Louis, Mosby, 1995; pp. 755-780.

56. Rossi A, Ranieri MV. Positive end-expiratory pressure. In: Tobin MJ, ed. Principles and Practice of Mechanical Ventilation. New York, McGraw-Hill, 1994; pp. 259-303.

57. Brandolese R, Broseghini C, Polese G, et al. Effects of intrinsic PEEP on pulmonary gas exchange in mechanically-ventilated patients. Eur Respir J 1993; 6: 358-363.

58. Gattinoni L, Marcolin R, Caspani ML, et al. Constant mean airway pressure with different patterns of positive pressure breathing during the adult respiratory distress syndrome. Bull Eur Physiopathol Respir 1985; 21: 275-279.

59. Rossi A, Appendini L. Wasted efforts and dyssynchrony: is the patient-ventilator battle back? Intensive Care Med 1995; 21: 867-870.

60. Tobin MJ, Alex CG. Discontinuation of mechanical ventilation. In: Tobin $\mathrm{M}$, ed. Principles and Practice of Mechanical Ventilation. New York, McGraw Hill, 1994; pp. 1177-1206.

61. Bernasconi M, Ploysongsang Y, Gottfried SB, MilicEmili J, Rossi A. Respiratory compliance and resistance in mechanically-ventilated patients with acute respiratory failure. Intensive Care Med 1988; 14: 547-553.

62. Tantucci C, Corbeil C, Chassé M, Braidy J, Matar N, Milic-Emili J. Flow resistance in patients with chronic obstructive pulmonary disease in acute respiratory failure. Am Rev Respir Dis 1991; 144: 384-389.

63. Polese G, Rossi A, Appendini L, Brandi G, Bates JHT, Brandolese R. Partitioning of respiratory mechanics in mechanically ventilated patients. J Appl Physiol 1991; 71: 2425-2433.

64. Ranieri M, Giuliani R, Cinnella G, et al. Physiologic effects of positive end-expiratory pressure in patients with chronic obstructive pulmonary disease during acute ventilatory failure and controlled mechanical ventilation. Am Rev Respir Dis 1993; 147: 5-13.

65. Guérin C, Coussa ML, Eissa NT, et al. Lung and chest wall mechanics in mechanically ventilated COPD patients. J Appl Physiol 1993; 74: 1570-1580.

66. Rossi A, Appendini L, Poggi R, Ganassini A, Brandolese R, Luzzani A. Acute bronchial asthma: indications for intensive care. Eur Respir Rev 1993; 3: 400-403.

67. Gay PC, Rodarte JR, Tayyab M, Hubmayr RD. Evaluation of bronchodilator responsiveness in mechanically ventilated patients. Am Rev Respir Dis 1987; 136: 880-885.

68. Bernasconi M, Brandolese R, Poggi R, Manzin E, Rossi A. Dose-response and time course effects of inhaled fenoterol on respiratory mechanics and arterial oxygen tension in mechanically ventilated patients with chronic airflow obstruction. Intensive Care Med 1990; 16: 108-114.

69. Dhand R, Tobin MJ. Bronchodilator delivery with metered-dose inhalers in mechanically ventilated patients. Eur Respir J 1996; 9: 585-595.

70. Corbridge TC, Hall JB. The assessment and management of adults with status asthmaticus. Am J Respir Crit Care Med 1995; 151: 1296-1316.

71. Fink JB, Dhand R, Duarte AG, Jenne JW, Tobin MJ. 
Aerosol delivery from a metered-dose inhaler during mechanical ventilation. Am J Respir Crit Care Med 1996; 154: 382-387.

72. Dhand RD, Duarte AG, Jubran A, et al. Dose-response to bronchodilator delivered by metered-dose inhaler in ventilator-supported patients. Am J Respir Crit Care Med 1996; 154: 388-393.

73. National Heart, Lung and Blood Institute. Global initiative for asthma. NHLBI7WHO workshop report, March 1993. NHLBI, publication No. 95-3659, January 1995.

74. Calverley PMA. Symptomatic bronchodilator treatment. In: Calverley $\mathrm{N}$, ed. Chronic Obstructive Pulmonary Disease. London, Chapman \& Hall, 1995; pp. 419-445.

75. Fernandez A, Munoz J, De la Calle B, et al. Comparison of one versus two bronchodilators in ventilated COPD patients. Intensive Care Med 1994; 20: 199-202.

76. Poggi R, Brandolese R, Bernasconi M, Manzin E, Rossi A. Doxophylline and respiratory mechanics. Chest 1989; 96: 772-778.

77. Aubier M, Decramer M. Respiratory muscle pharmacology. In: Roussos C, ed. The Thorax. New York, Dekker, 1995; pp. 2341-2366.

78. Thompson WH, Nielson CP, Carvalho P, Charan NB, Crowley JJ. Controlled trial of oral prednisone in outpatients with acute COPD exacerbation. Am J Respir Crit Care Med 1996; 154: 407-412.

79. Decramer M, De Bock V, Dom R. Functional and histologic picture of steroid-induced myopathy in chronic obstructive pulmonary disease. Am J Respir Crit Care Med 1996; 153: 1958-1964.

80. Rossi A, Ganassini A, Tantucci C, Grassi V. Aging and the respiratory system. Aging Clin Exp Res 1996; 8: $143-161$.
81. Rubini F, Rampulla C, Nava S. Acute effect of corticosteroids on respiratory mechanics in mechanically ventilated patients with chronic airflow obstruction and acute respiratory failure. Am J Respir Crit Care Med 1994; 149: 306-310.

82. Maltais F, Sovilj M, Goldberg P, Gottfried SB. Respiratory mechanics in status asthmaticus: effect of inhalational anesthesia. Chest 1994; 106: 1401-1406.

83. D'Angelo E, Calderini E, Torri G, Robatto FM, Bono D, Milic-Emili J. Respiratory mechanics in anesthetized paralyzed humans: effects of flow, volume and time. $J$ Appl Physiol 1989; 67: 2556-2564.

84. Darioli R, Domenighetti G, Perret C. Mechanical ventilation for severe respiratory failure in status asthmaticus. Prog Respir Res 1980; 14: 266-270.

85. Darioli R, Perret C. Mechanically controlled hypoventilation in status asthmaticus. Am Rev Respir Dis 1984; 129: 385-387.

86. Feihl F, Perret C. Permissive hypercapnia: how permissive should it be? Am J Respir Crit Care Med 1995; 150: 1722-1737.

87. Rossi A, Brandolese R, Milic-Emili J, Gottfried SB. The role of PEEP in patients with chronic obstructive pulmonary disease during assisted ventilation. Eur Respir $J$ 1990; 3: 818-822.

88. Kolouris NG, Valta P, Lavoie A, et al. A simple method to detect expiratory flow limitation during spontaneous breathing. Eur Respir J 1995; 8: 306-313.

89. Valta P, Corbeil C, Chassé M, Braidy J, Milic-Emili J. Mean airway pressure as an index of mean alveolar pressure. Am J Respir Crit Care Med 1996; 153: 1825- 1830.

90. Polese G, Lubli P, Mazzucco A, Luzzani A, Rossi A. Respiratory mechanics and expiratory flow limitation in patients before and after heart surgery. Eur Respir $J$ 1995; 8: 78S. 